\author{
Konstantin V. Vershinin, Marianna Yu. Andreycheva \\ Institute of Russian History of the Russian Academy of Sciences, Moscow, Russia
}

\title{
OLD RUSSIAN ETHNOGENEALOGICAL TREATISE (PART 1)
}

The paper introduces a hitherto uninvestigated piece of Old Russian literacy - a nameless text. Given its content, it is proposed to qualify it as an ethnogenealogical treatise. The authors know the piece from Metropolitan Macarius' Great Menaion Reader, two more copies of the $17^{\text {th }}$ century and two fragments of the early $15^{\text {th }}$ and $17^{\text {th }}$ centuries. The basis of the text is a commentary on Psalm 82 aligned with the contents of the entry for the year 6604 (1096) of the Primary Chronicle. The forepart of the paper provides an edition of the piece and an archaeographic commentary. It is concluded that the full copies of the treatise contain farther additions. The original shape of the piece is reconstructed. A detailed study is expected in the latter part of the paper.

Keywords: ethnogenealogy, $\rho_{\text {rimary }}$ Chronicle, $\rho_{\text {salm }}$ 82, Great Menaion Reader, Old Russian literacy

\author{
УДК 94(47).043 ББК 63.3(2)44 DOI 10.25986/IRI.2019.75.1.004 \\ Чарльз Дж. Гальперин chalperi@indiana.edu \\ Институт России и Восточной Европь Университета Индианы, США. chalperi@indiana.edu
}

\section{ХАН И ЭЛИТА: МОСКОВСКОЕ ВОСПРИЯТИЕ ПОЛИТИЧЕСКОЙ КУЛЬТУРЫ КРЫМСКОГО ХАНСТВА В ПЕРИОД ПРАВЛЕНИЯ ИВАНА IV}

Михаил Хоп предположил, что в рамках политической культуры Монгольской империи и ее преемников было две традиџии: безграничная власть правителя, такого как Чингисхан, и коллегиальная консенсуальная власть - курултай. Согласно московским посольским книгам (Крымским делам) времени правления Ивана IV, московский двор воспринимал политическую культуру Крымского ханства, преемника Улуса Джучи, как сообразную второй парадигме - консенсуального коллегиального государства. Ключевые слова: Иван IV, Москва, Крымское ханство, элита, политическая культура, консенсуальный, коллегиальный

Дискуссия о татарском влиянии на политическую структуру России меняет направление при смене интерпретаџии природы монгольской политической культуры. Во времена «холодной войны» Монгольская империя и ее преемники считались примерами восточного деспотизма, поэтому утверждалось, что Улус Джучи (Золотая Орда) превратила Россию в восточный деспотизм [Wittfogel]. Когда историки, спеџиализируюшиеся на внутренней Азии, стали подчеркивать коллегиальные и консенсуальные элементы Монгольской империи, некоторые спеџиалисты по Московской Руси стали интерпретировать такие черты московской политической культуры, как Дума и Земский собор, как продукты татарского влияния [Ostrowski, 1990; Ostrowski, 1998, р. 1-132; Ostrowski, 2002; Ostrowski, 2004]. Теперь М. Хоп сделал убедительное предположение, что монгольская политическая культура содержала две политические традиџии: одна - фактически безграничной монархической власти, олиџетворяемая в первую очередь властью самого Чингисхана, вторая - консенсуального коллегиального правления, институџионализированная, среди прочего, в проведении курултаев для решения политических и военных задач [Норе]. Поэтому Москва могла унаследовать или заимствовать от татар и авторитарную и консенсуальную модели политической культуры.

Источники времени правления Ивана IV предоставляют значимые свидетельства того, как московская политическая элита воспринимала политическую культуру Крымского ханства - «внука» мировой Монгольской империи. Крымские дела из посольских книг дают детальную информаџию об отношениях Московии с Крымским ханством. Две недавно опубликованные книги предоставили историкам доступ к богатым архивным свидетельствам ${ }^{1}$. В Посольском приказе составили последовательный дипломатический нарратив из исходных материалов записок, инструкџй, посланий и отчетов своих чиновников ${ }^{2}$. Московско-крымские дипломатические контакты были особенно интенсивными между 1567 и 1577 г., включая оттоманско-крымскую попытку завоевать Астрахань в 1569 г., сожжение крымчанами Москвы в 1571 г. и битву при Молодях в 1572 г.

Московские переводчики не имели сложностей при взаимодействии с оттоманизированным крымским тюркским языком дипломатической корреспонденџии из Крыма в Москву, хотя переписчики порой путали тюркские имена [Малов, с. 20].

Московская элита владела обширными знаниями о политической ситуаџии в Крыму. Московия зналаперсонально всех политических игроков Крымского ханства. Иван IV и иногда царевич Иван переписывались с большинством из них. Входящие и исходяшие грамоты были сохранены в государственном архиве, хотя, очевидно, переписку с второстепенными членами элиты не включили в посольские книги [Виноградов, 2015, с. 33]. Корреспонденџией обменивались не только с ханом (џарем) Девлет-Гиреем, но и с его офиџиальным наследником - калгой, царевичем

1 Посольская книга по связям Московского государства с Крымом 1571-1577 гг. / Отв. ред. И. В. Зайџев; подгот. текста А. В. Малов, О. С. Смирнова, Г. А. Тарасова; статьи, комментарии А. В. Виноградов, И. В. Зайџев, О. С. Смирнова, В. Н. Сокуров; приложения А. М. Галенко, И. А. Мустакимов (далее - ПК 1571-1577). М., 2015; Посольская книга по связям Московского государства с Крымом 1567-1572 / Отв. ред. М. В. Моисеев; подгот. текста А. В. Малов, О. С. Смирнова; статьи, комментарии А. В. Виноградов, И. В. Зайџев, А. В. Малов, М. В. Моисеев (далее - ПК 1567-1572). М., 2016. Эти выпуски перекрываются хронологически [Малов, с. 4].

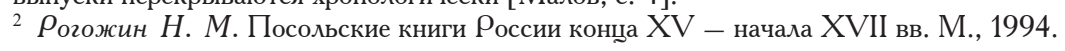


(султаном) Магмет-Гиреем (Мухаммед-Гиреем) и с другими џаревичами (ханскими сыновьями): Абдыл-Гиреем, Алп-Гиреем, Ислам-Гиреем, Казы-Гиреем, Бити-Гиреем, Мубарек-Гиреем и Саип-Гиреем, а также старшим сыном калги Саадат-Гиреем³. Учитывая понимание Москвой той роли знатных женшин - жен и матерей Чингисидов, которую они играли в политике Крыма, подобные коммуникаџии распространялись и на татарских женшин. Иван обменивался письмами с џариџей (ханшей, женой хана) Анабиим-хатунь (Аиша-Салтан, Аиша-Сатма-Салтан), первой женой Девлет-Гирея и матерью калги Магмет-Гирея и Айль-Гирея, и другими его женами: Хансюр (Хан Суюр, Хан Сурет), а также с Ханикей, Перхан, Хантотай и Ширван. Москва также коммуниџировала с политически активными нечингисидами под предводительством князя (бека) Сулеша (Сулейман-шаха), амиата, посредника в дипломатических отношениях между Московией и ханством, который утверждал, что он и его сыновья были слугами Ивана; беками или князьями Сулейман-ишаном (Сулейманши), Мурад-мурзой, Ахмет-мурзой пашой, Арасланом-Мурзой и Янши-Пашой - все они иногда назывались «сыновьями Сулеша» (Сулешовы); с МуртазаМиразом и его братом Мустафой-Ага, князем Касыма или Касима, членом дивана; князем Дивеем и карачибегом ${ }^{4}$, главой Мангыта или клана Мансура, и князем Ази из клана Ширина; все они считались приближенными людьми [Виноградов, 2015, с. 54], вместе с Муслы-аталыком и Дербиш-аталыком. Гонџы из Крыма приносили письма Ивану от хана, калги, џаревичей, џариџ, князей и мурз (мирз, нечингисидской знати) $)^{5}$.

Князь Сулеш и его сыновья были агентами Москвы, но так же было и с другими крымчанами. Князь МустафаАга писал Ивану, что его правое плечо служит хану Девлет-Гирею, а его левое плечо служит Ивану6.

Москва не избегала попыток влиять на решения о персоналиях в Крыму, особенно на то, кого хан послал бы в Москву. Московский посол предлагал хану отправить в качестве послов одного из трех ближних людей: Гамзамирзу брата Мустафы, или Сефер-мирзу брата Мурата, или аталыка Дервиша, или, по крайней мере, кого-то из хорошего крымского племени ${ }^{8}$.

Московские посольские книги описывали политическую культуру Крымского ханства как коллегиальную и консенсуальную, требуюшую от хана советоваться со своей элитой при принятии важных решений. Москва, без сомнения, настаивала, чтобы элита ратифиџировала действия хана, такие как вступление в альянс с Москвой. Крымское ханство в ответ настаивало, чтобы их политические решения были ратифиџированы и ханом, и правящим кланом, и элитой. Даже более интригуюшим является тот факт, что московские чиновники разрабатывали московскую политическую терминологию в отношении Крымского ханства, используя для рассказа о крымских делах московский политический дискурс.

При описании совета хана со своей элитой, посольские книги используют московский термин: проведение Думы. Сам совет передавался глаголом придумати․ Хан проводил некий съезд, думу ${ }^{10}$. Он не только проводил думу с уланами (огланами, элитной кавалерией), князьями и карачи-беями, но и формулировка согласия участников консультаџий выражалась в Крымских делах еше одним словом из московского политического дискурса: карачибеи приговорили с ханом ${ }^{11}$. Ср. в московских декретах: џарь указал и бояре приговорили ${ }^{12}$.

Девлет-Гирей и џаревичи думали с князем Селимом, атаковать ли московскую граниџу ${ }^{13}$. Девлет также обсуждал послание Ивана с џаревичами, карачи, уланами, князьями и мурзами ${ }^{14}$. Посланники от џаря, џаревичей, џариџ, князей и мирз ездили в Москву ${ }^{15}$. Москва настаивала, что принесения присяги только Девлетом недостаточно, чтобы пребывать в условиях предложенного московско-крымского альянса: калга, џаревичи, карачи, уланы, князья, мурзы, аталыки (опекуны, или наставники, дословно «дяди» Чингисидов, как правило, младших) все должны принять присягу ${ }^{16}$. А. В. Малов в своих комментариях описывает собрание, в котором ханская элита приносила присягу, как курултай ${ }^{17}$. Девлет-Гирей обешал, что если Иван отдаст ему и его сыновьям Казань и Астрахань, то џаревичи, карачи, князья, хорошие дворяне (другой московский термин для членов двора, царского домохозяйства), князья и все уланы принесут «сильную шерть» Ивану ${ }^{18}$.

Калга Магмет-Гирей писал Ивану, что его отеџ объявил перед всеми карачи-беями и лучшими людьми (обычное выражение в московских источниках) о своем желании дружбы между Москвой и Крымом ${ }^{19}$.

3 См.: Именной указатель // ПК 1567-1572. С. 380-931; Аннотированный именной указатель // ПК 1571-1577. С. 343-365 (в этом указателе упомянуты все имена крымчан).

4 Карачи (буквально: черные) беги были главами четырех из пяти главных крымских кланов, составлявших вершину клановоплеменной аристократии нечингисидов [Schamiloglu].

${ }^{5}$ ПК 1571-1577. С. 223-224.

6 Там же. С. 253.

7 В основном Крым посылал в Москву гонџов, имевших более низкий дипломатический статус.

${ }^{8}$ ПК 1571-1577. С. 258.

${ }^{9}$ ПК 1567-1572. С. 78, 96.

10 Там же. С. 101.

11 Там же. С. 114.

12 Любопытно, что в книге «Крымские дела» я не нашел ни одного предложения, где бы упоминалось, что хан «указал».

13 ПК 1571-1577. С. 65.

${ }_{14}$ ПК 1567-1572. С. 161, 172.

${ }^{15}$ ПК 1571-1577. С. 61.

${ }_{16}$ ПК 1567-1572. С. 91.

17 Там же. С. 362, примеч. ххі.

${ }^{18}$ ПК 1571-1577. С. 83-84.

19 Там же. С. 87. 
В посольских книгах записано, что Девлет с џаревичами, карачи-беями, уланами, князьями, мирзами и всей землей приговорили к союзу с королем Польши ${ }^{20}$. Џаревичи, князья, мирзы и «вся земля» сказали Девлету напасть на Белёв, Одоев и Козельск, и хан, царевичи и «вся земля» приговорили напасть на Козельск ${ }^{21}$. Крымский посол доказывал Москве, что хан Девлет, калга Магмет-Гирей, џаревичи и вся Крымская земля желают мира и дружбы с Московией ${ }^{22}$. Обрашение ко «всей земле» или к «Крымской земле» соответствовало «земельной» системе обозначения государств на Руси, сформулированной во время киевского периода, наиболее известной по конџепту Русской земли. Такая «земельная» терминология появилась не среди степных кочевников, чья самоидентификаџия была организована вокруг людей, а не территории. Однако некоторые историки интерпретируют аллюзии к «землям» среди татар как ссылку на курултай.

Москва просила хана послать Ивану ближнего человека ${ }^{23}$, такой же термин использовался для ближних людей в Московском кремле и обозначал членов Ближней думы ${ }^{24}$. Многие князья были ближними людьми ${ }^{25}$. Московские послы должны были узнать, какие из князей были ближними людьми ${ }^{26}$. Иван в послании Алей-Мирзе из клана Ширинов, принадлежашего к четырем кланам карачи, польстил ему замечанием, что Иван слышал, будто хан и калга обращали внимание на него во всякой ближней думе ${ }^{27}$. Я не думаю, что это ссылка на институт, называемый Ближней Думой, как в Москве. А. В. Виноградов предполагает, что ближняя дума означает диван в смысле «Совет» ${ }^{28}$, возможно, «совет» четырех карачи-беев.

Московский посол в Крыму утверждал, что не только хан, но также џаревичи, карачи, князья, уланы и приближенные люди клялись делать правду в своей присяге Ивану ${ }^{29}$. Если Девлет сперва поклялся делать правду Ивану один, без каких-либо князей, царевичей, карачей или уланов, позднее он выпустил шертную грамоту, в которой он, все его џаревичи, карачи, князья и уланы поклялись делать правду Ивану ${ }^{30}$.

Когда Иван просил Девлета отправить его сына Мурат-мирзу в Путивль в качестве посла, ханские карачи и князья, а не Девлет, ответили, что это было бы неудобно ${ }^{31}$. Московским послам было велено расположиться с князьями, мурзами, царским человеком или любыми ближними џарскими персонами ${ }^{32}$.

Аналогии между Крымом и Москвой простираются даже на низшие слои соџиальной структуры. Московским послам велено установить мнение о московском альянсе черных людей - этим термином московские источники обозначали низшие классы ${ }^{33}$. Представитель Москвы в Крыму сообщал, что џаревичи, все князья, мирзы и черные люди хотели быть в мире с Москвой. Он идентифиџировал ряд ближних людей хана: князь Мурат Сулешев сын, князь Касим Куликов и князь Мурат-Казы. Князь Мустафа и его брат князь Муртоза-Ага всегда сопровождали хана. Сулеш князь Перекопский и Муслы-аталык всюду сопровождали калгу. Џаревич Абдыл нигде не ходил без князя Сефера Сулешева сына Муратова, младшего сына князя Сулеша ${ }^{34}$.

На такие вопросы Сулеша, любых ближних людей, других князей или мирз, как: почему Москва не послала писем или подарков отдельной миссией ханской матери, другим џариџам или младшим џаревичам, а послала лишь Девлету, калге и другим младшим царевичам, представители Москвы в Крыму должны были ответить, что это все потому, что в настояшее время дружбы между Москвой и Крымом не было, но Москва могла бы продолжить посылать свои шедрые дары большему кругу элиты, когда бы дружба была восстановлена ${ }^{35}$.

Москва отмечала, что даже среди Гиреев, не говоря уже об элите в џелом, отсутствует единодушие, что было могло быть только в случае, если хан не смог его обеспечить. Посольский приказ велел послу тайно проведать, враждовал ли калга со своими братьями. Любили ли князья и мирзы калгу Магмет-Гирея? Хотели ли они, чтобы Магмет-Гирей принял трон, когда умрет хан Девлет-Гирей, или они более благоволили его брату Абдыл-Гирею либо другому џаревичу? ${ }^{36}$ Если же Девлет-Гирей умер и пока никто не заменил его, то подарки Ивана, посланные Девлету, следует отдать матери калги Магмет-Гирея, џариџе Анабиим, чтобы та отдала их своему сыну Магмету, а дары, которые Иван послал Магмету, также следует передать Анабиим, чтобы та передала их следуюшему џаревичу на очереди к трону Абдыл-Гирею. Посол должен был обратиться к хану, кем бы он ни был, и поошрить князей и мирз, ставших новыми ближними людьми, кем бы они ни были. В случае же вторжения туреџкого султана, который

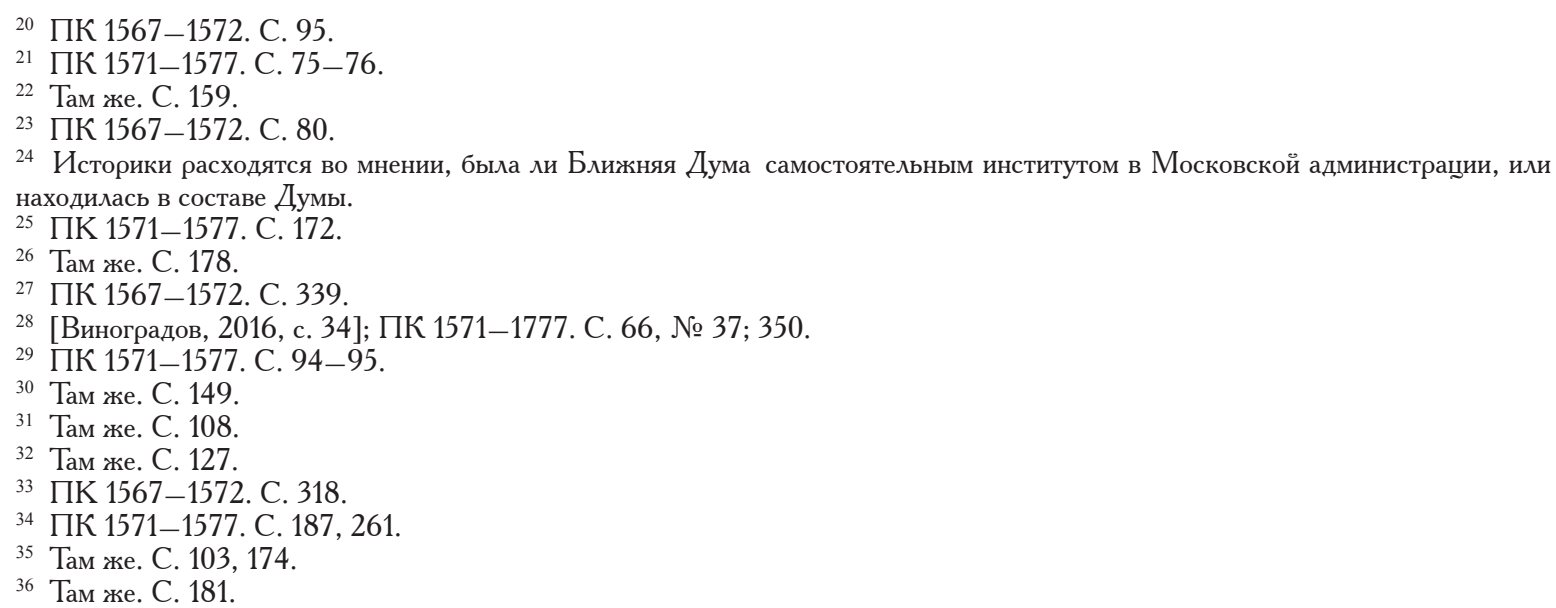


не посадит на трон никого из сыновей Девлет-Гирея, посол должен действовать по ситуаџии ${ }^{37}$. Можно выделить два элемента этих планов с непредвиденными обстоятельствами: первый - непременное уважение к старшей жене хана, и второй - невозможность видения Девлет-Гирея абсолютным правителем. Если бы Девлет пользовался безграничной властью, то все, что ему следовало сделать, чтобы посадить на трон своего преемника, - это объявить имя своего сына в качестве наследника, независимо от того, чего хотела крымская әлита, а тем более султан.

Выводы: хорошо информированный московский дипломатический истеблишмент не пребывал в иллюзии, что крымский хан был восточным деспотом, который самостоятельно мог определять внешнюю политику своего ханства. При принятии решений хан должен был советоваться со своей элитой, Чингисидами и нечингисидами и делал это. Хан понимал, что он обязан демонстрировать эти советы, и неоднократно показывал Москве, что элита согласна с принятыми решениями. Московские послы настаивали, чтобы хан согласовывал свои решения с элитой, дабы избежать использования ханом недостаточного единодушия в качестве оправдания за невыполнение его обешаний Москве. В московских посольских источниках крымский хан никогда не действовал в одностороннем порядке, не утверждал, что действовал единолично, и это было требованием Москвы. В глазах Москвы политическая структура Крымского ханства второй половины XVI в. следовала за согласованной, консенсуальной традиџией Монгольской империи.

Более того, политическая структура Крымского ханства также имела обшие черты с московской политической структурой. Правитель в каждой из них функџионировал в условиях того же дискурса консультаџий в рамках совместимых придворных структур: хан и его ближние люди встречались в Думе, элита приговаривала все решения, элита включала лучших людей и придворных, членов џарской семьи и дворян [Bogatyrev]. Внимание к женшинам отличало Крымский двор от Московского.

Этот вывод можно рассмотреть в контексте восприятия Москвой ее степных соседей. Во-первых, монахи составители Степенной книги в 1560 -х годах приписывали решения в Казанском ханстве до его завоевания Москвой в 1552 г. членам ханского двора и мусульманскому религиозному истеблишменту [Halperin, 2010а]. Крымские дела не упоминали улемов.

Во-вторых, в их статейных списках московский дипломатический корпуспродвигал свою собственнуюсоџиальную и политическую терминологию при дворах Швеции, Англии и Священной Римской империи в большей степени, чем при дворе Оттоманской империи, воспринимая Истамбул как куда меньший по значению, чем Москва, в отличие от Стокгольма, Лондона или Вены [Halperin, 2010b]. Казалось, что московиты считали Крымское ханство гораздо больше напоминавшим Московию, чем Оттоманская империя. Очевидно, все государства, основанные степными кочевниками внутренней Азии, в умах московитов не были подобными. Возможно, присутствие Чингисидов на иностранном троне было ключевой детерминантой московских отношений. Этот аспект восприятия московитами Степи требует дальнейшего изучения.

\section{Литература}

Виноградов A. B., Малов $A$. В. Четырнадџатая крымская посольская книга в русско-крымских отношениях 1571-1577 гг. // Посольская книга по связям Московского государства с Крымом 1571-1577 гг. / Отв. ред. И. В. Зайџев; подгот. текста А. В. Малов, О. С. Смирнова, Г. А. Тарасова; статьи, комментарии А. В. Виноградов, И. В. Зайџев, О. С. Смирнова, В. Н. Сокуров; приложения А. М. Галенко, И. А. Мустакимов. М., 2015. C. 31-59.

Виноградов A. В. Русско-крымские отношения 1567-1572 гг. в тринадџатой крымской посольской книге // Посольская книга по связям Московского государства с Крымом 1567-1572 / Отв. ред. М. В. Моисеев; подгот. текста А. В. Малов, О. С. Смирнова; статьи, комментарии А. В. Виноградов, И. В. Зайџев, А. В. Малов, М. В. Моисеев. М., 2016. С. 34-45.

Малов A. B. Состав и структура Тринадџатой крымской посольской книги (1567-1572 гг.) (На правах археографического предисловия) // Посольская книга по связям Московского государства с Крымом 1567-1572 / Отв. ред. М. В. Моисеев; подгот. текста А. В. Малов, О. С. Смирнова; статьи, комментарии А. В. Виноградов, И. В. Зайиев, А. В. Малов, М. В. Моисеев. М., 2016. С. 7-28.

Bogatyrev S. The Sovereign and His Counsellors. Ritualised Consultations in Muscovite Political Culture, 1350s-1570s. Saarijärvi, 2000.

Halperin Ch. J. The Muscovite Attitude toward the Outside World During the Reign of Ivan IV: Stepennaia kniga // Актуальные проблемы истории и культуры татарского народа. Материалы к учебным курсам: в честь юбилея академика АН РТ М. А. Усманова / Сост. Д. А. Мустафина и М. С. Гатин; ред. И. Я. Гилязов, Казань, 2010. C. 188-201. [Halperin, 2010a]

Halperin Ch. J. Russia between East and West: Diplomatic Reports during the Reign of Ivan IV // Saluting Aaron Gurevich: Essays in History, Literature and Other Subjects / Ed. in Y. Mazour-Matusevich and A. S. Korros. Leiden, 2010. P. 81-103. [Halperin, 2010b]

Hope M. Power, Politics and Tradition in the Mongol Empire and the Ilkhanate of Iran. Oxford, 2016.

Ostrowski D. The Mongol Origins of Muscovite Political Institutions // Slavic Review. 1990. Vol. 49. P. 525-542.

Ostrowski D. Muscovy and the Mongols. Cross-cultural influences on the steppe frontier. Cambridge, 1998.

Ostrowski D. The Façade of Legitimacy: Exchange of Power and Authority in Early Modern Russia // Comparative Studies in Society and History. 2002. Vol. 44. P. 534-563.

37 Там же. С. 281-285. 
Ostrowski D. The Assembly of the Land (Zemskii sobor) as a Representative Institution // Modernizing Muscovy: Reform and Social Change in Seventeenth-Century Russia / Ed. by J. Kotilaine and M. 1 Poe. London, 2004. P. 117-141. Schamiloglu U. The Qaraci Beys of the Late Golden Horde: Notes on the Organization of the Mongol World Empire // Archivum Eurasiae Medii Aevi. 1984. Vol. 4. P. 283-297.

Wittfogel K. A. Oriental Despotism. A Comparative Study of Total Power. New Haven, 1957.

\author{
Charles J. Halperin \\ Russian and East European Institute of Indiana, USA
}

\title{
THE KHAN AND THE ELITE: THE MUSCOVITE PERCEPTION OF THE POLITICAL CULTURE OF THE CRIMEAN KHANATE DURING THE REIGN OF IVAN IV
}

Michael Hope suggested that within the framework of the political culture of the Mongol empire and its successors there were two traditions: the unlimited power of a ruler, such as Chingiz-Khan, and collegial consensual power, such as the qurultai. According to the Moscow embassy books (Crimean affairs) of the reign of Ivan IV, the Moscow court perceived the political culture of the Crimean Khanate, the successor of Ulus Juchi, as consistent with the second paradigm a consensual collegial state.

Keywords: Ivan IV, Muscovy, Crimean Khanate, elite, political culture, consensual, collegiate

\author{
УДК 9.94 ББК 63.3(2)4 DOI 10.25986/IRI.2019.75.1.005 \\ Т. В. Гимон \\ ИВИ РАН, Москва, \\ НОВГОРОДСКИЕ ВААДЫЧНЫЕ ЛЕТОПИСЏЫ \\ ВТОРОЙ ТРЕТИ ХІV - НАЧАЛА ХV в.
}

А. А. Гиппиус выявил в тексте Новгородской I летописи моменты смены архиепископских летописџев, пополнявших летопись в XII - начале XIV в. Аналогичные выводы были сделаны А. Г. Бобровым в отношении текста за XV в. B настояшей статье делается ряд наблюдений над промежуточным текстом, за 1331-1421 г., позволяюших предварительно говорить о том, что в этот период, как и прежде, и впоследствии, летописџы, как правило, сменялись вслед за их патронами - архиепископами.

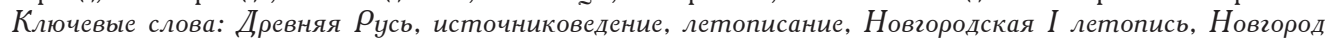

Предпринятый А. А. Гиппиусом [Гиппиус, 1996, с. 13-26; Гиппиус, 2006] систематический анализ языка и стиля статей Новгородской I летописи (далее - H1) за XII - начало XIV в. позволил выявить моменты смены авторов. В большинстве случаев эти моменты совпадают по времени (точно или примерно) со сменами архиепископов, а значит, летописание в Новгороде велось из года в год и было владычным². Как показывает пример пономаря Тимофея (XIII в.), атакже, вероятно,КирикаиГерманаВояты (XIІв.),владычнымилетописцамибыликлирики,исполнявшиепопоручению архиепископов и ряд секретарских обязанностей [Гиппиус, 1992; Гиппиус, 1996, с. 23]. Результаты исследования А. А. Гиппиуса открыли новые возможности как лингвистического, так и источниковедческого исследования новгородской летописи: теперь мы можем сопоставлять язык конкретных летописцев, манеру их работы, круг интересов, взгляды и т. д.

Для XV в. сегментаџию новгородской летописи предложил А. Г. Бобров. «Техническим руководителем» «непрерывно ведушейся летописи» начала XV в. ученый считает Матфея Кусова (см. подробнее ниже). Последняя статья, которую А. Г. Бобров связывает с деятельностью Матфея, - 6929 (1421) г. [Бобров, 2001, с. 80-84, 180]. Летописание времени Феодосия (1421-1424), который был избран на волне восстания, но так и не рукоположен, дошло до нас, по мнению А. Г. Боброва, в виде жалких фрагментов в Н1 младшего извода (далее - Н1мл.), поскольку подверглось ревизии при Евфимии I [Бобров, 2001, с. 84-89]. Следующй сегмент - «весьма лапидарные» записи времени Евфимия I (до статьи Н1мл. 6936 (1428) г.) [Бобров, 2001, с. 90-91]. При Евфимии II, согласно А. Г. Боброву, велась активная сводческая работа, но в то же время делались и погодные записи, отразившиеся в разных сводах [Бобров, 2001, с. 186-194, 218, 231-233 и др.]. Анализируя способы датировок, А. Г. Бобров показал, что на рубеж статей 6965-6966 (1457-1458) г. приходится граниџа между летописями архиепископов Евфимия II (ум. 1458) и Ионы [Бобров, 2008]. В двух списках Новгородской IV летописи сохранились, согласно А. Г. Боброву, новгородские записи за 14701476 г., стиль которых резко отличается от статей за предыдушие годы. После смерти владыки Ионы (в 1470 г.) офиџиальное летописание перешло, согласно ученому, «в руки магистрата», то есть стало на короткое время светским [Бобров, 2001, с. 238-239]. Наконеџ, последний (перед утратой Новгородом независимости) фрагмент «городского» летописания предположительно дошел до нас в статье 6985 (1477) г. Устюжской летописи [Бобров, 2001, с. 239-240].

А. Тимберлейк предложил сегментаџию текста Лаврентьевской летописи за 6685-6701 (11771203) г. [Timberlake, 2000]. Мои наблюдения над тематикой сообщений и формуляром известий о џерковном

${ }^{1}$ Статья подготовлена в Государственном академическом университете гуманитарных наук в рамках госзадания Минобрнауки России (проект № 33.1221.2017/ПЧ). Новгородская І летопись џитируется по изданию: ПСРЛ. М., 2000. Т. 3.

${ }^{2}$ То и другое было понятно и раньше (см. отсылки: [Гимон, 2005, с. 318-319]), но получило теперь весьма солидное подтверждение. 